\title{
A Rare Genetic Disorder in Modern Ages - Goldenhar Syndrome
}

\author{
Shalini Subramanyam ${ }^{1 *}$ and Peeyush Shivhare ${ }^{2}$ \\ ${ }^{1}$ Private Practitioner, Oral and Maxillofacial Pathologist, Bangalore, India \\ ${ }^{2}$ Oral Medicine Consultant and Oral Radiology Specialist, Nobel Medical College and \\ Teaching Hospital, Nepal \\ *Corresponding Author: Shalini Subramanyam, Oral and Maxillofacial \\ Pathologist, Bangalore, India.
}

Received: September 10, 2020

Published: October 22, 2020

(C) All rights are reserved by Shalini

Subramanyam and Peeyush Shivhare.

\begin{abstract}
Goldenhar syndrome (GS) also known as oculoauriculovertebral dysplasia is a relatively common developmental disorder characterized by craniofacial anomalies in association with ocular, auricular, vertebral, cardiac, renal, central nervous system and maxillofacial defects. This condition was first described in 1952 by the Swiss ophthalmologist, Maurice Goldenhar. The incidence of this condition varies from 1 in 3,500 to 1 in 5,600 live births. Goldenhar syndrome needs to a multidisciplinary approach regarding craniofacial and cardiologic associations. We are presenting a case of $19 \mathrm{yr}$ old male who was diagnosed with Goldenhar syndrome.
\end{abstract}

Keywords: Goldenhar Syndrome; Facial Asymmetry; Malformation

\section{Introduction}

Goldenhar syndrome (GS), also known as oculoauriculovertebral dysplasia or hemifacial microsomia is a rare hereditary condition characterized by numerous anomalies affecting the first and second branchial arches of the first pharyngeal pouch, the first branchial cleft and the primordia of the temporal bone. It consists of wide range of clinical manifestations, including craniofacial, vertebral, cardiac, renal and central nervous system anomalies. The typical presentation of GS includes epibulbar dermoids, microtia, mandibular hypoplasia and vertebral anomalies [1,2].

This condition was first described in 1952 by the Swiss ophthalmologist, Maurice Goldenhar Gorlin., et al. (1963) included vertebral anomalies as signs of the syndrome and suggested the name oculoauriculovertebral (OAV) dysplasia for this condition. Smith (1978) used the term facio-auriculo-vertebral sequence to include both Goldenhar syndrome and hemifacial microsomia [2].

\section{Case Report}

A 19 yr old male reported to oral medicine and radiology department for regular check up. There was no relative dental and medical history. Patient's parents gave a family history of consanguineous marriage.

General Physical examination revealed scoliosis and constricted thorax (Figure 1 and 2). Vital signs were within normal limits. Extraoral examination revealed facial asymmetry (deviation to right side), long face, deviation of nasal bridge to left side, malformed left ear with pre-auricular auricular tags, pannus on right eye, absence of wrinkles on left side of forehead, absence of nasolabial fold on left side and drooping of lower lip on right side (Figure 3-8). Mouth opening was normal (35 mm) with deflection towards left side (Figure 9). Intraorally there was anterior open bite, cross bite posteriorly on right side, midline shift towards left side, Deep Dentinal Caries wrt 46 (Figure 10). No other important clinical extraoral or intraoral findings were observed. Based on clinical findings, a provisional diagnosis of Goldenhar syndrome was given.

After clinical examination radiographic examinations were performed. Panoramic radiograph showed hypoplastic left ramus, body, condyle and coronoid process compared to right side (Figure 11). P.A view showed facial asymmetry, haziness in right maxillary 
sinus (Figure 12). CT was advised for additional information. CT revealed soft tissue thickening in right maxillary sinus suggesting chronic sinusitis, hypoplastic coronoid process on left side, deviated nasal bone on left side, deviated nasal septum on right side (Figure 13 and 14). Chest x-ray confirmed scoliosis with multiple vertebral abnormalities. After radiographic confirmation patient was advised complete systemic evaluation and referred to General medicine, cardiology, ophthalmology, ENT and orthopedics. Eye examination showed pannus on right eye. Ear examination showed hearing loss on left ear. Echo showed acynotic congenital heart disease with bicuspid aortic valve. Karyotyping showed no abnormality.

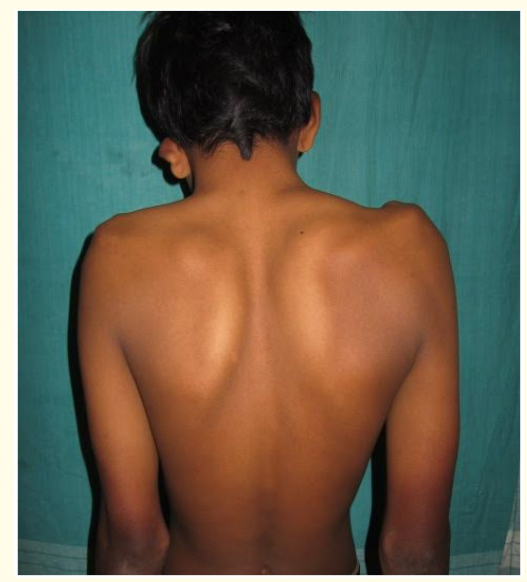

Figure 1

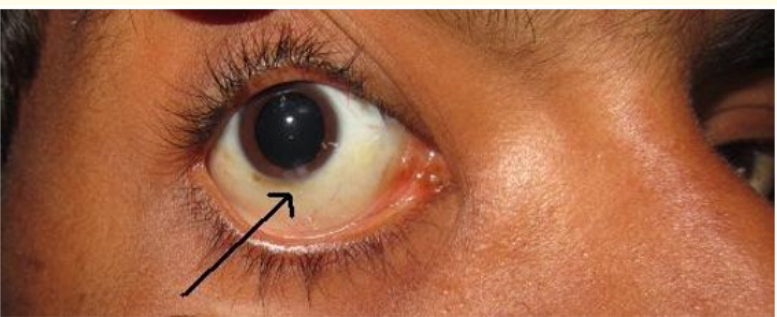

Figure 2

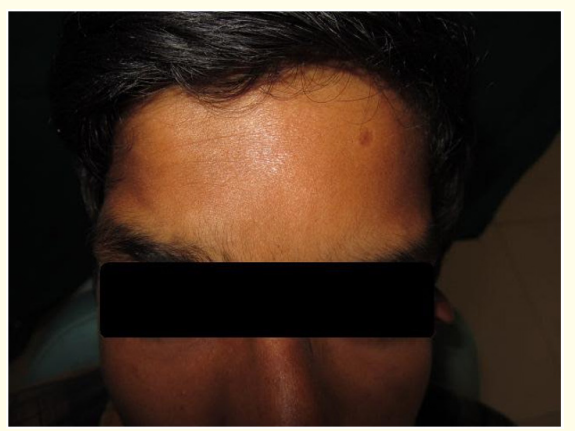

Figure 3

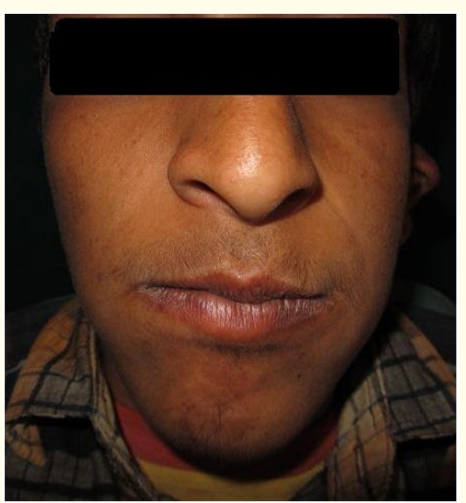

Figure 4

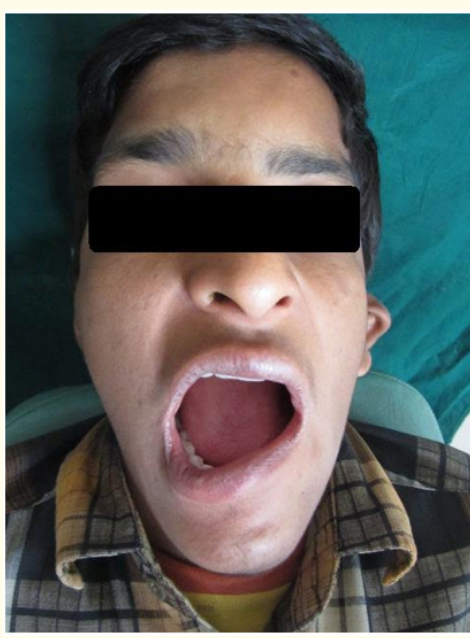

Figure 5

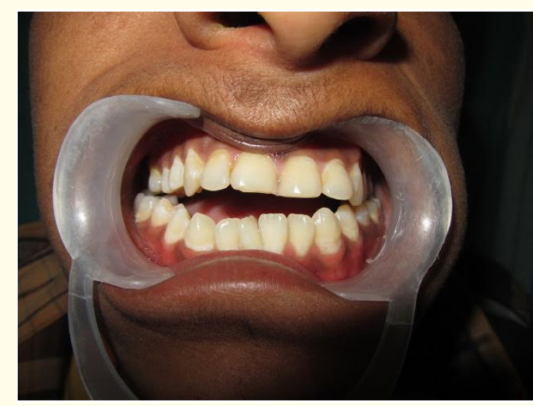

Figure 6

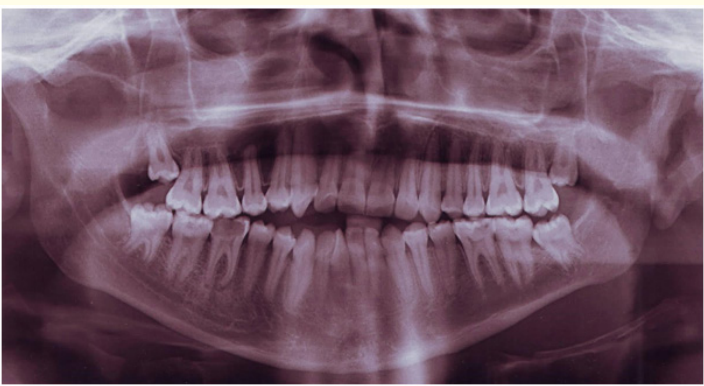

Figure 7 


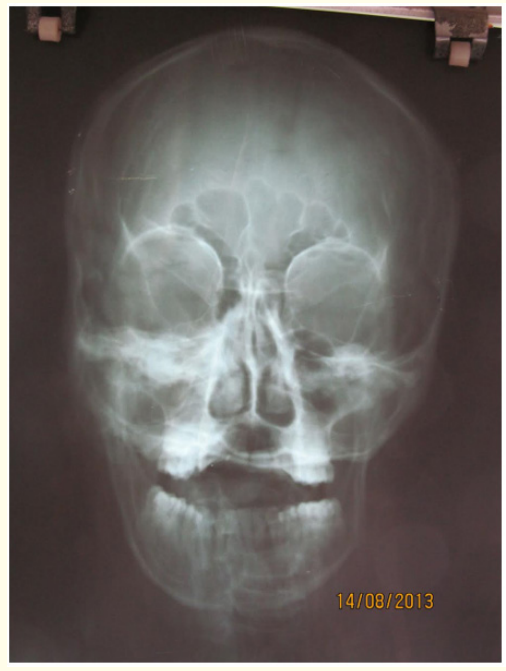

Figure 8

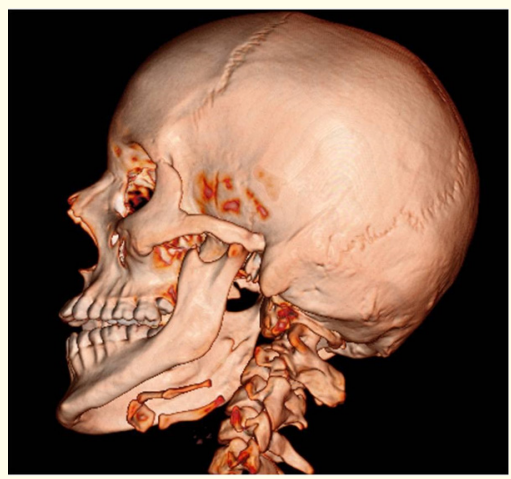

Figure 9

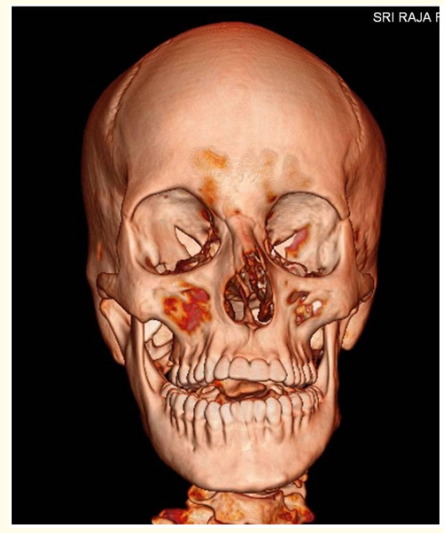

Figure 10

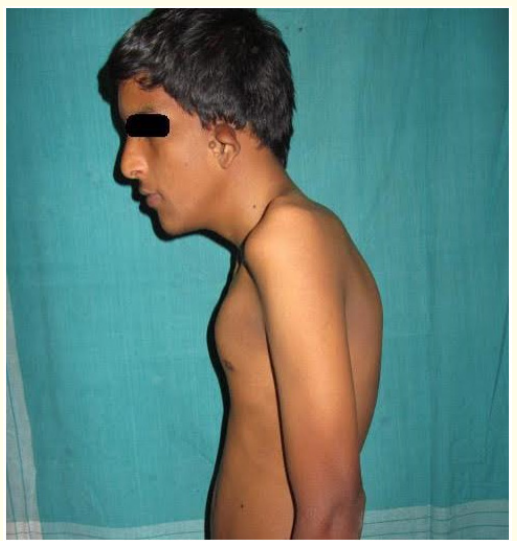

Figure 11

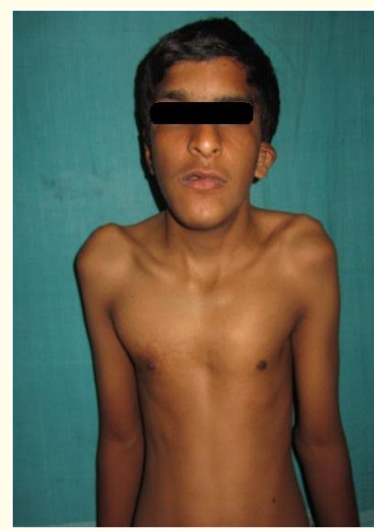

Figure 12

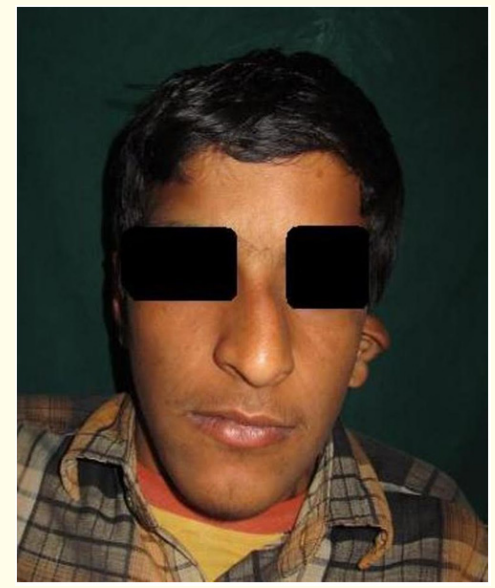

Figure 13 


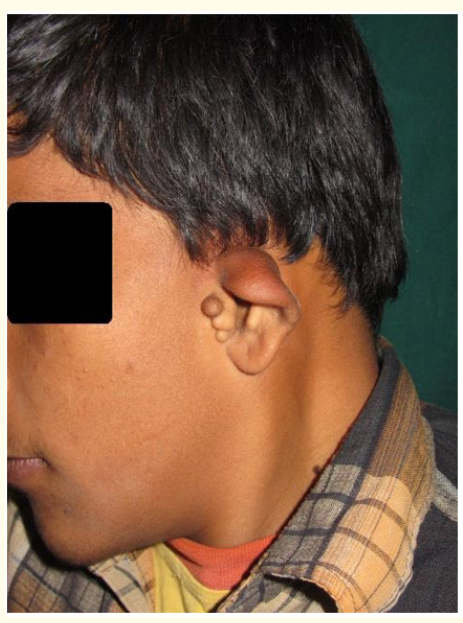

Figure 14

Based on the clinical and radiographic findings, a final diagnosis of Goldenhar syndrome was given. Patient was referred to orthodontist and ENT specialist for the best possible treatment.

\section{Discussion}

The many terms used for this complex indicate the wide spectrum of anomalies described and emphasized by various authors. The complex has been known as hemifacial microsomia, oculo-auriculovertebral dysplasia, facio-auriculo-vertebral dysplasia, Goldenhar syndrome, Goldenhar-Gorlin syndrome, first arch syndrome, first and second branchial arch syndrome, lateral facial dysplasia, unilateral craniofacial microsomia, otomandibular dysostosis, unilateral Mandibulofacial dysostosis, unilateral intrauterine facial necrosis, auriculo-branchiogenic dysplasia and facio-auriculo-vertebral malformation complex $[3,4]$.

The incidence of this condition varies from 1 in 3,500 to 1 in 5,600 live births and it is present in 1 in 1,000 children with congenital deafness. The male: female ratio of patients is approximately 3:2 and there is also a 3:2 predilection for right-sided ear involvement $[3,5,6]$.

There is not enough information to identify its etiologic factors. Recent research has investigated the potential interaction of environmental factors with genes, and the findings suggest the possibility of multifactorial inheritance [7].

On the other hand, another study suggested a disturbance of the neural crest cells as the cause of the disease [8]. The influence of other factors, including the environment during pregnancy has also been blamed. The ingestion of some drugs such as cocaine, thalidomide, retinoic acid, and tamoxifen by the mother were also related to the development of the disease [9]. Maternal diabetes has also been suggested as an etiologic factor [10].

Several chromosomal anomalies have been associated including del(5p), del(6q), trisomy 7 mosaicism, del(8q), trisomy 9 mosaicism, trisomy 18, recombinant chromosome 18, del(18q), ring 21 chromosome, del(22q), dup(22q), trisomy 22, 49,XXXXX, 49,XXXXY and 47,XXY. In some cases, even normal karyotyping has been found $[2,3,11]$ so genetic karyotyping is not a confirmatory aid in the diagnosis.

In a classic Goldenhar syndrome patient auricular malformations include preauricular skin tags or blind fistulas, microtia, or other external ear malformations like asymmetries, aplasias, dysplasias and atresias of the external meatus), middle and internal ear anomalies. Optic malformations includes epibulbar dermoid or lipodermoid (mostly bilateral), colobomas of the upper eyelid, iris, chorioid and retina, or other eye anomalies (e.g. microphthalmia, anophthalmia, cataract, astigmatism, antimongoloid obliquity of palpebral fissures and blepharophimosis). Vertebral column anomalies includes atlas occipitalization, synostosis, hemivertebrae, fused vertebrae, scoliosis, and bifid spine. Maxillofacial manifestation includes unilateral facial hypoplasia, prominent forehead, hypoplasia of the zygomatic area and maxillary and mandibular hypoplasia, Unilateral macrostomia (lateral facial cleft) [2].

Dentofacial anomalies may include cleft lip and palate, a crease over the lateral commissure of the mouth, a highly arched palate, hypoplasia of the maxillary and mandibular arches, micrognathia, gingival hypertrophy, supernumerary teeth, enamel and dentin malformations, and delayed tooth development. Malocclusion and macrostomia due to the presence of an underdeveloped lower jaw have also been observed. Moreover, patients often show asymmetric development of the muscles of the masticatory system and agenesis of salivary glands [5].

Principal deformities of the Goldenhar syndrome are often combined with various malformations, such as Cleft lip and/or palate, tongue cleft, unilateral tongue hypoplasia, and parotid gland aplasia, Rib anomalies and anomalies of the extremities, Congenital heart disease (ventricular septal defects), anomalies of the urogenital and gastrointestinal system (ectopic kidneys, ureteropelvic 
junction obstruction and imperforate anus), anomalies of the central nervous system (occipital encephalocele), anomalies of the larynx and lungs (tracheoesophageal fistula, esophageal atresia) and Complex retardation of mental development [2].

The effect of Goldenhar syndrome is more evident as the child grows, because of delays in the growth and development of the affected areas. The lack of development of the upper and lower jaws can cause breathing problems, as well as dental malocclusion, which require surgical and/or orthodontic treatment. There are several methods of surgical treatment, such as conventional surgical procedures (costochondral rib graft and classical osteotomy) and the distraction technique. Using the distraction technique, it is possible to lengthen the jaw and the ramus of the mandible to the desired size; however, this technique does not result in normal growth and function of the temporomandibular joint. In addition, there is a risk of mild infection during the period of lengthening [5].

\section{Conclusion}

While there is no cure for Goldenhar syndrome, treatment and management of specific symptoms and features of the disorder can often be successful. It is necessary to carryout genetic advising and carry multimode treatment approach is indicated to prevent the late effects.

\section{Bibliography}

1. Anderson PJ amd David DJ. "Spinal anomalies in Goldenhar Syndrome". The Cleft Palate-Craniofacial Journal 42 (2005): 477-480.

2. Kokavec R. "Goldenhar syndrome with various clinical manifestations". The Cleft Palate-Craniofacial Journal 43 (2006): 628-634.

3. Gorlin RJ., et al. "Branchial arch and pralacral disorders". Syndromes of head and neck. $4^{\text {th }}$ edition. Oxford university press: 790-796.

4. Jongbloet PH. "Goldenhar syndrome and overlapping dysplasias in vitro fertilisation and ovopathy". Journal of Medical Genetics 24 (1987): 616-620.

5. Bielicka B., et al. "Interdisciplinary treatment of patients with Goldenhar syndrome - clinical reports". Dental and Medical Problems 43 (2006): 458-462.

6. Kulkarni VV., et al. "Goldenhar syndrome: a case report". Journal of Postgraduate Medicine 31 (1985): 177-179.
7. Tuna EB., et al. "Craniofacial and dental characteristics of Goldenhar syndrome: a report of two cases". Journal of Oral Science 53.1 (2011): 121-124.

8. Rodríguez JI., et al. "Severe axial anomalies in the oculo-auriculo-vertebral (Goldenhar) complex". American Journal of Medical Genetics 47 (1993): 69-74.

9. Lessick M., et al. "Severe manifestations of oculoauriculovertebral spectrum in a cocaine-exposed infant". Journal of Medical Genetics 28 (1991): 803-804.

10. Araneta MRG., et al. "Goldenhar syndrome among infants born in military hospital to Gulf war veterans". Teratology 56 (1997): 244-251.

11. Wilson GN and Barr Jr M. "Trisomy 9 mosaicism: Another etiology for the manifestations of Goldenhar Syndrome". Journal of Craniofacial Genetics and Developmental Biology 3 (1983): 313-316.

\section{Assets from publication with us}

- Prompt Acknowledgement after receiving the article

- Thorough Double blinded peer review

- Rapid Publication

- Issue of Publication Certificate

- High visibility of your Published work

Website: www.actascientific.com/

Submit Article: www.actascientific.com/submission.php

Email us: editor@actascientific.com

Contact us: +919182824667 